\title{
Bioprocessing of tea oil fruit hull with acetic acid organosolv pretreatment in combination with alkaline $\mathrm{H}_{2} \mathrm{O}_{2}$
}

Song Tang ${ }^{1,2}$, Rukuan Liu ${ }^{3}$, Fubao Fuelbiol Sun ${ }^{1 *}$, Chunying Dong ${ }^{3}$, Rui Wang ${ }^{3}$, Zhongyuan Gao ${ }^{1,4}$, Zhanying Zhang ${ }^{5}$, Zhihong $\mathrm{XiaO}^{3}$, Changzhu $\mathrm{Li}^{3}$ and Hui $\mathrm{Li}^{3^{*}}$

\begin{abstract}
Background: As a natural renewable biomass, the tea oil fruit hull (TOFH) mainly consists of lignocellulose, together with some bioactive substances. Our earlier work constructed a two-stage solvent-based process, including one aqueous ethanol organosolv extraction and an atmospheric glycerol organosolv (AGO) pretreatment, for bioprocessing of the TOFH into diverse bioproducts. However, the AGO pretreatment is not as selective as expected in removing the lignin from TOFH, resulting in the limited delignification and simultaneously high cellulose loss.

Results: In this study, acetic acid organosolv (AAO) pretreatment was optimized with experimental design to fractionate the TOFH selectively. Alkaline hydrogen peroxide (AHP) pretreatment was used for further delignification. Results indicate that the AAO-AHP pretreatment had an extremely good selectivity at component fractionation, resulting in $92 \%$ delignification and $88 \%$ hemicellulose removal, with $87 \%$ cellulose retention. The pretreated substrate presented a remarkable enzymatic hydrolysis of $85 \%$ for $48 \mathrm{~h}$ at a low cellulase loading of $3 \mathrm{FPU} / \mathrm{g}$ dry mass. The hydrolyzability was correlated with the composition and structure of substrates by using scanning electron microscopy, confocal laser scanning microscopy, and X-ray diffraction.
\end{abstract}

Conclusion: The mild AAO-AHP pretreatment is an environmentally benign and advantageous scheme for biorefinery of the agroforestry biomass into value-added bioproducts.

Keywords: Tea oil fruit hull, Acetic acid, Alkaline $\mathrm{H}_{2} \mathrm{O}_{2}$, Mild pretreatment, Delignification, Enzymatic hydrolysis

\section{Background}

Camellia oleifera Abel., originated from China at least as early as 2300 years ago, is an evergreen boscage or small tree in Camellia family. Currently, it is widely planted in some Asian countries, predominantly in China. As an edible oil crop, its seed is mainly used for extruding nourishing oils enriched with unsaturated fatty acids, high up to $90 \%$, which is reported to be the highest content in edible oils [1]. The unsaturated fatty acids mainly consist

\footnotetext{
*Correspondence: fubaosun@jiangnan.edu.cn; lihuiluoyang@163.com ${ }^{1}$ Key Laboratory of Carbohydrate Chemistry and Biotechnology, Ministry of Education, School of Biotechnology, Jiangnan University, Wuxi 214122 China

${ }^{3}$ National Engineering Research Center for Oil-tea Camellia, Hunan Academy of Forestry, Changsha 410004, China

Full list of author information is available at the end of the article
}

of oleic acid and linoleic acid, in which the oleic acid content $(75-87 \%)$ is $5-10 \%$ higher than that of the olive oil [2]. Thus, the cooking oil, known as "eastern olive oil" in China, almost has met the international nutritional standards of "omega meals." Accordingly, the Camellia oleifera Abel. crop has attracted huge economic interests in China. In recent years, the plantation of C. oleifera has increased by a yearly rate of $5.4 \%$ [3]. As byproducts from the tea oil processing industry, the outputs of tea oil fruit hull (TOFH), seed shell, and oil cake have reached around 5 million tons every year [4]. It has been estimated that more than 10 million tons of tea oil processing byproducts will be generated with a plantation area of 6 million hectares by 2020 [1].

Traditionally, these byproducts are discarded away or burned up in the tea oil processing industry, which not 
only causes environmental concerns but also is a waste of bioresources. Considering of rich bioactive substances in the seed shell and oil cake, much attention has been paid to valorization of these byproducts $[3,5]$. However, the use of TOFH is very limited, though it accounts for $~ 75 \%$ of these total byproducts [6]. As a natural lignocellulosic biomass, the TOFH consists of $12-14 \%$ cellulose, $19-21 \%$ hemicellulose, and $26-27 \%$ lignin, in addition to the rich bioactive substances (i.e., tea saponin and tannin) [5, 7]. Attempts have been made to process $C$. oleifera Abel hull into diverse bioproducts using a two-stage solvent-based process, which includes one aqueous ethanol organosolv (AEO) extraction step, followed by an atmospheric glycerol organosolv (AGO) pretreatment [7]. With the mild AEO treatment, the extraction of tea saponin and tannin reached above $80 \%$, respectively. However, the severe AGO pretreatment $\left(180{ }^{\circ} \mathrm{C}, 3 \mathrm{~h}\right)$ is not so selective as expected in altering the main composition, resulting in a low delignification (34\%), a low hemicellulose removal (40\%), but a high cellulose loss (18\%) from the TOFH. Thus, more efforts are addressed to find an alternative method to pretreat the AEO-extracted TOFH.

As a common organic solvent, acetic acid organosolv (AAO) pretreatment has been proved to be efficient in selectively fractionating the lignocellulosic biomass into cellulose pulp, lignin, and hemicellulose under mild conditions [8-11]. The AAO lignin is desirable for many important applications due to its low molecular weight and high reactivity $[8,12]$. Pan and Sano [9] removed $75 \%$ of lignin and $83 \%$ of hemicellulose from wheat straw under atmospheric AAO pretreatment condition $\left(105^{\circ} \mathrm{C}\right.$, $\left.3 \mathrm{~h}, 4 \% \mathrm{H}_{2} \mathrm{SO}_{4}\right)$. Atmospheric AAO pretreatment has some appealing advantages, i.e., mild process and good selectivity. Although AAO pretreatment has been applied on common lignocellulosic biomass (rice straw, wheat straw, sugarcane bagasse, and hard wood), it has not been evaluated yet on TOFH.

On the other hand, alkaline hydrogen peroxide (AHP) pretreatment can lead to significantly improved hydrolyzability by further delignification [13, 14]. The AHP pretreatment has gained an increasing interest in the further delignification by combination with other pretreatment methods [11], i.e., steam explosion [15], dilute acid [16-18], concentrated phosphoric acid [19], and alkaline $[20,21]$. Zhu et al. [15] removed 92\% lignin from E. ulmoides wood with the steam explosion pretreatment followed by AHP, and thereby achieved a high glucose yield of above $90 \%$. To our knowledge, there is very little information reported to date on a combination of the AAO pretreatment with the AHP acting on the lignocellulosic biomass $[18,22]$.

In this study, an AAO pretreatment followed by AHP was evaluated as a mild process to fractionate the
AEO-extracted TOFH selectively. Firstly, the mild AAO process was optimized with a statistical analysis to find key variables determinant to the good selectivity and hydrolyzability. Secondly, the AHP pretreatment was used to further improve the enzymatic hydrolysis of AAO-pretreated substrates. Structural features were characterized with modern analytic equipment including scanning electron microscopy (SEM), confocal laser scanning microscopy (CLSM), and X-ray diffraction (XRD). The fractionation of AAO- and AAO-AHP-pretreated substrates was correlated with these physio-chemical features. Finally, mass balance analysis was conducted for the mild AAO-AHP pretreatment process.

\section{Results and discussion}

\section{Construction of the AAO pretreatment process}

Numerous researchers have demonstrated that variables such as pretreatment temperature, pretreatment time, acetic acid concentration, and acid catalyst contribute to the AAO pretreatment of lignocellulosic biomass $[8$, 23]. Accordingly, these variables were taken into careful consideration by using Plackett-Burman design (PBD), steepest ascent design, and central composite design (CCD) in this study.

According to the PBD (Table 1; Additional file 1: Tables S1 and S2), these variables had a significant effect $(P<0.05)$ on the pretreatment except cellulose retention. Given that lignin impedes substantially substrate hydrolyzability through non-productive binding of cellulase enzymes to its surface and/or through steric hindrance [24], the delignification was taken as an exclusive dependent variable for AAO pretreatment. In addition to the pretreatment temperature, the other three variables were taken into consideration to maximize a delignification from the lignocellulosic biomass. Based on the steepest ascent design experiment (Table 2), the pretreatment condition (acetic acid 50\%, pretreatment time $1.63 \mathrm{~h}$ and $\mathrm{H}_{2} \mathrm{SO}_{4}$ addition $0.58 \%$ ) was selected as the central point of the CCD for further optimization using CCD (Additional file 1: Tables S3-S6).

For the CCD, 20 experiments were carried out (Additional file 1: Table S4). The regression model was highly statistically significant $(P<0.0001)$, but the lack of fit was not significant $(P=0.357>0.1)$ (Additional file 1 : Table S5). Meanwhile, relatively lower value $(1.97<10 \%)$ of variation coefficient indicated the good precision and reliability of these experiments. Adequate precision for our model had a signal-to-noise ratio of $34.2(>4)$, meaning an adequate signal. Under these circumstances, each variable and the interaction of every two variables also had a remarkable effect $(P<0.05)$ (Additional file 1: Table S6). The best model was identified using the coefficient of determination $R^{2}(0.989)$, suggesting that $98.9 \%$ of the 
Table 1 PBD experimental result of the AAO pretreatment

\begin{tabular}{|c|c|c|c|c|c|c|c|c|}
\hline \multirow[t]{2}{*}{ Runs } & \multirow[t]{2}{*}{$x_{1}$} & \multirow[t]{2}{*}{$x_{2}$} & \multirow[t]{2}{*}{$x_{3}$} & \multirow[t]{2}{*}{$x_{4}$} & \multicolumn{4}{|l|}{ Response (\%) } \\
\hline & & & & & Cellulose retention & Hemicellulose retention & Delignification & Pretreatment yield \\
\hline 1 & 0.5 & 20 & 0.7 & 135 & 90.2 & 91.0 & 11.9 & 85.9 \\
\hline 2 & 2.0 & 20 & 0.2 & 115 & 91.3 & 95.7 & 7.3 & 87.8 \\
\hline 3 & 0.5 & 60 & 0.7 & 135 & 96.8 & 19.8 & 67.1 & 35.9 \\
\hline 4 & 0.5 & 60 & 0.2 & 115 & 88.3 & 94.8 & 9.6 & 94.7 \\
\hline 5 & 2.0 & 20 & 0.7 & 135 & 90.8 & 11.4 & 33.8 & 39.9 \\
\hline 6 & 0.5 & 20 & 0.7 & 115 & 89.0 & 93.0 & 11.4 & 88.0 \\
\hline 7 & 2.0 & 60 & 0.2 & 135 & 92.2 & 28.7 & 52.9 & 42.7 \\
\hline 8 & 2.0 & 60 & 0.7 & 115 & 96.3 & 21.6 & 60.0 & 33.4 \\
\hline 9 & 2.0 & 60 & 0.7 & 115 & 96.0 & 22.8 & 58.9 & 40.7 \\
\hline 10 & 0.5 & 20 & 0.2 & 115 & 90.0 & 95.8 & 9.5 & 94.1 \\
\hline 11 & 0.5 & 60 & 0.2 & 135 & 87.7 & 87.7 & 23.1 & 80.6 \\
\hline 12 & 2.0 & 20 & 0.2 & 135 & 91.3 & 48.3 & 27.0 & 57.7 \\
\hline
\end{tabular}

$X_{1}$ time, $X_{2}$ acetic acid concentrations, $X_{3} \mathrm{H}_{2} \mathrm{SO}_{4}$ addition, $X_{4}$ pretreatment temperature

Table 2 Steepest ascent experiment of AAO pretreatment

\begin{tabular}{lllll}
\hline Runs & $\begin{array}{l}\boldsymbol{X}_{\mathbf{1}} \\
\text { Time (h) }\end{array}$ & $\begin{array}{l}\boldsymbol{X}_{\mathbf{2}} \\
\text { Acetic acid (\%) }\end{array}$ & $\begin{array}{l}\boldsymbol{X}_{\mathbf{3}} \\
\mathbf{H}_{\mathbf{2}} \mathbf{S O}_{\mathbf{4}} \text { addition } \\
(\%)\end{array}$ & $\begin{array}{l}\text { Delignification } \\
(\%)\end{array}$ \\
\hline 1 & 1.3 & 40 & 0.45 & 23.2 \\
2 & 1.4 & 45 & 0.51 & 37.7 \\
3 & 1.6 & 50 & 0.58 & 60.1 \\
4 & 1.8 & 55 & 0.64 & 64.1 \\
5 & 2.0 & 60 & 0.70 & 66.3 \\
6 & 2.2 & 65 & 0.76 & 67.3 \\
7 & 2.4 & 70 & 0.83 & 68.3 \\
\hline
\end{tabular}

sample variation was attributed to the variables. For a regression model, the present $R^{2}$ value (0.978) reflected a very good fit of the observed and predicted responses, implying that the model is reliable for delignification with AAO pretreatment (Additional file 1: Figure S1). The maximum delignification obtained by using above selected variables was $70.0 \%$, and the experimental maximum obtained was $69.0 \pm 0.6 \%$. The data show that predicted data on the response from empirical model were in agreement with those observed in the range of the operating variables. The coefficients of regression were calculated, and the following regression equation was obtained.

$$
\begin{aligned}
Y= & 4.91+4.88 \times X_{1}+3.74 \times X_{2}+5.72 \times X_{3} \\
& +0.42 \times X_{1} \times X_{2}-1.74 \times X_{1} \times X_{3}-1.62 \\
& \times X_{2} \times X_{3}-2.79 \times X_{1}^{2}-2.34 \\
& \times X_{2}^{2}-1.98 \times X_{3}^{2}
\end{aligned}
$$

where $Y=$ Response (Delignification), $X_{1}=$ Pretreatment time, $X_{2}=$ Acetic acid concentration, and $X_{3}=\mathrm{H}_{2} \mathrm{SO}_{4}$ addition in coded values.

To understand that the effect of these variables on the delignification during the AAO pretreatment, the predicted model was presented as 3D/2D response surface graphs, as shown in Fig. 1. These variables were optimized as follows: pretreatment time $1.72 \mathrm{~h}, \mathrm{H}_{2} \mathrm{SO}_{4}$ addition $0.64 \%$, and acetic acid content $52.6 \%$ for the AAO pretreatment. Under optimized condition, the removal of lignin and hemicellulose reached 68 and $86 \%$, respectively. It means that there were $44.3 \%$ cellulose, $11.8 \%$ hemicellulose, and $25.7 \%$ lignin existing in the AAOpretreated substrate. The result is comparable to that reported elsewhere on the AAO pretreatment (Table 3). Like other common (agricultural or woody) lignocellulosic biomass, the AAO pretreatment has selectively removed most of the lignin and hemicellulose from the TOFH with an almost intact cellulose retention [12]. Notably, the optimal pretreatment conditions mentioned in these publications are obviously different, which is seemingly due to the variety of lignocellulosic feedstock. These results have indicated that the AAO pretreatment is as effective for selectively disintegrating the lignocellulosic byproduct of tea oil processing industry as other lignocellulosic biomass.

\section{Enzymatic hydrolysis of AAO-pretreated substrates}

Enzymatic hydrolysis of the AAO-pretreated substrates was used to evaluate for its hydrolyzability in this experiment. As shown in Fig. 2a, the enzymatic hydrolysis of AAO-pretreated substrates increased with a big enzyme loading, reaching $\sim 90 \%$ for $48 \mathrm{~h}$ at $25 \mathrm{FPU} / \mathrm{g} \mathrm{DM}$. The 


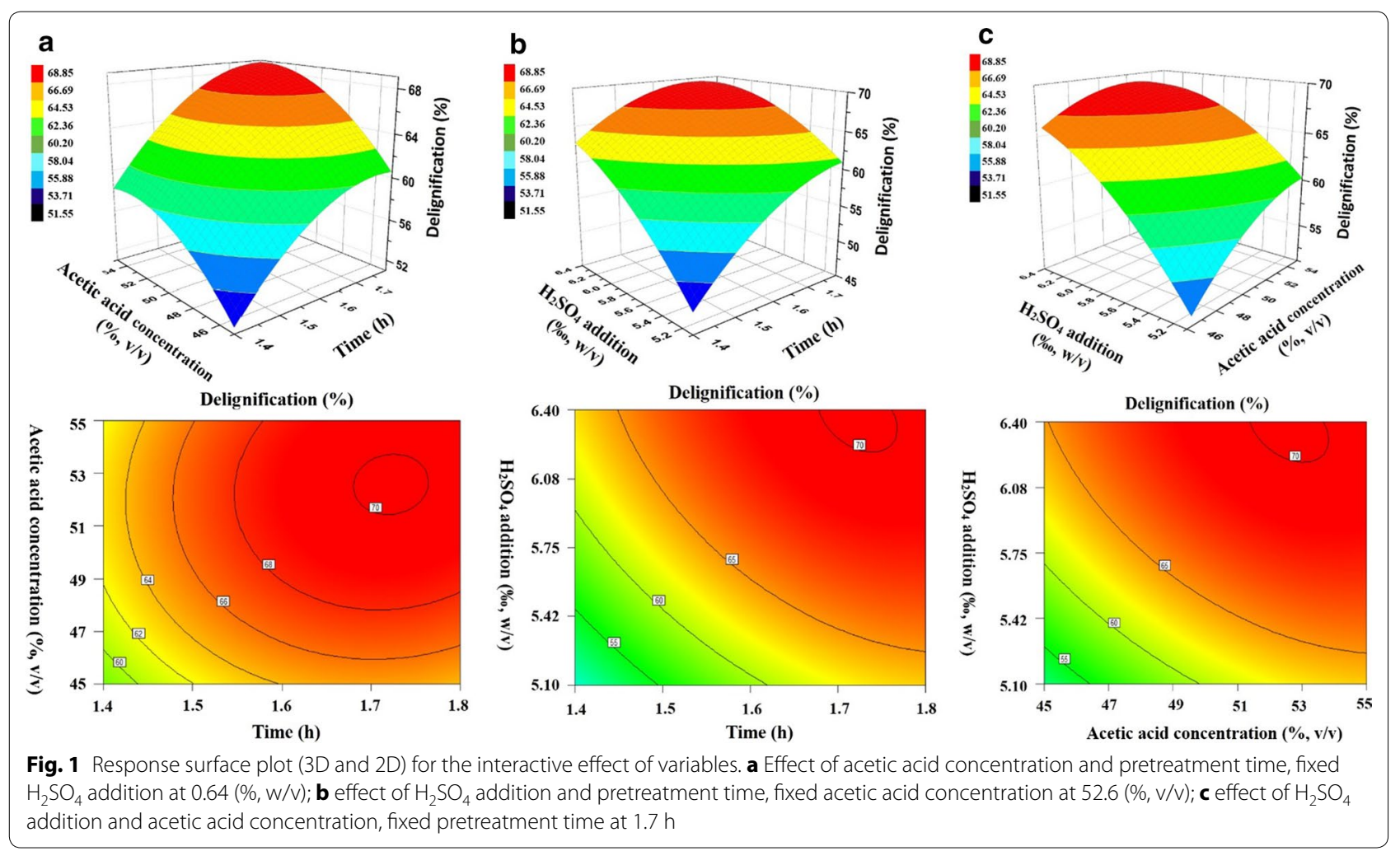

Table 3 Comparison of the AAO-AHP pretreatment with others on lignocellulosic biomass

\begin{tabular}{|c|c|c|c|c|c|c|c|c|c|c|}
\hline \multirow[t]{3}{*}{ Feedstock } & \multicolumn{6}{|c|}{ Pretreatment process } & \multicolumn{3}{|c|}{$\begin{array}{l}\text { Resulting } \\
\text { solids }\end{array}$} & \multirow[t]{3}{*}{ Source } \\
\hline & \multirow[t]{2}{*}{ Type } & \multicolumn{4}{|l|}{ Pretreatment } & \multirow[t]{2}{*}{ Post-pretreatment } & \multirow{2}{*}{$\begin{array}{l}\mathrm{C} \\
\%\end{array}$} & \multirow[t]{2}{*}{$\mathbf{H}$} & \multirow[t]{2}{*}{$\mathbf{L}$} & \\
\hline & & Content (\%) & Catalyst & $\mathrm{T}\left({ }^{\circ} \mathrm{C}\right)$ & Time (h) & & & & & \\
\hline C. inophyllum shell & $\mathrm{H}_{2} \mathrm{SO}_{4}+\mathrm{NaOH}$ & $1 \%$ & \multicolumn{4}{|c|}{ At $90^{\circ} \mathrm{C}$ for a fixed time } & 35 & 7 & 25 & Cheng et al. [26] \\
\hline E. ulmoides Oliver & $\mathrm{SEP}+\mathrm{AHP}$ & - & - & 213 & $1 / 3$ & $1.5 \% \mathrm{H}_{2} \mathrm{O}_{2}, \mathrm{pH} 11.5$ & 77 & 4 & 5 & Zhu et al. [15] \\
\hline Lespedeza stalk & $\mathrm{SEP}+\mathrm{AHP}$ & - & - & 184 & $1 / 15$ & $2 \% \mathrm{H}_{2} \mathrm{O}_{2}, \mathrm{pH} 11.5$ & 83 & 0 & 10 & Su et al. [27] \\
\hline $\mathrm{EFB}$ & $\mathrm{AAO}+\mathrm{AQA}$ & - & \multicolumn{4}{|c|}{7 (15) \% AAO (AQA) pretreatment at $180^{\circ} \mathrm{C}$ for $15 \mathrm{~min}$} & 65 & 22 & 21 & Kim et al. [22] \\
\hline Wheat straw & $\mathrm{AAO}$ & 90 & $0.4 \% \mathrm{H}_{2} \mathrm{SO}_{4}$ & 105 & 3 & - & 67 & 11 & 4 & Pan and Sano [9] \\
\hline Wheat straw & $\mathrm{AAO}$ & 80 & $8.5 \% \mathrm{HNO}_{3}$ & 120 & 0.3 & - & 96 & 3 & 1 & Sun et al. [38] \\
\hline Sugarcane straw & $\mathrm{AAO}$ & 80 & $0.3 \% \mathrm{HCl}$ & 120 & 3 & - & 61 & 7 & 12 & Saad et al. [23] \\
\hline Sugarcane bagasse & $\mathrm{AAO}$ & 90 & $0.1 \% \mathrm{H}_{2} \mathrm{SO}_{4}$ & 105 & 3 & - & 64 & 17 & 13 & Zhao et al. [10] \\
\hline Beech & $\mathrm{AAO}$ & 90 & $0.2 \% \mathrm{HCl}$ & 130 & 1 & - & 77 & 8 & 8 & Vila et al. [43] \\
\hline Corn stover & $\mathrm{HCl}+\mathrm{H}_{2} \mathrm{O}_{2}$ & - & $7 \% \mathrm{HCl}$ & 120 & $2 / 3$ & $3 \% \mathrm{H}_{2} \mathrm{O}_{2}+0.1 \% \mathrm{FeSO}_{2}$ & 26 & 2 & 12 & Li et al. [16] \\
\hline Wheat straw & $\mathrm{AAO}+\mathrm{AHP}$ & $55 \%$ & $30 \%$ FA & 105 & 3 & $1 \% \mathrm{H}_{2} \mathrm{O}_{2}$ & 70 & 15 & 2 & Snelders et al. [18] \\
\hline TOFH & $\mathrm{AGO}$ & 70 & - & 180 & 3 & & 22 & 26 & 27 & Sun et al. [7] \\
\hline TOFH & $\mathrm{AAO}$ & 53 & $0.6 \% \mathrm{H}_{2} \mathrm{SO}_{4}$ & 125 & 1.7 & - & 44 & 12 & 26 & This study \\
\hline TOFH & $A A O+A H P$ & 53 & $0.6 \% \mathrm{H}_{2} \mathrm{SO}_{4}$ & 125 & 1.7 & $3 \% \mathrm{H}_{2} \mathrm{O}_{2}, \mathrm{pH} 11.5$ & 65 & 15 & 10 & This study \\
\hline
\end{tabular}

EFB empty fruit bunches, $S E P$ steam explosion pretreatment, $A Q A$ aqueous ammonia, $F A$ formic acid, $C$ cellulose content, $H$ hemicellulose content, $L$ lignin content

result indicated that the lignocellulosic byproduct of tea oil processing industry was applicable as the feedstock for bioconversion, like other common lignocellulosic biomass $[9,22]$. As compared to that before the
AAO pretreatment (Fig. 2b), the enzymatic hydrolysis of AAO-pretreated substrates enhanced by more than three times, indicating a remarkable improvement of the substrate hydrolyzability. 

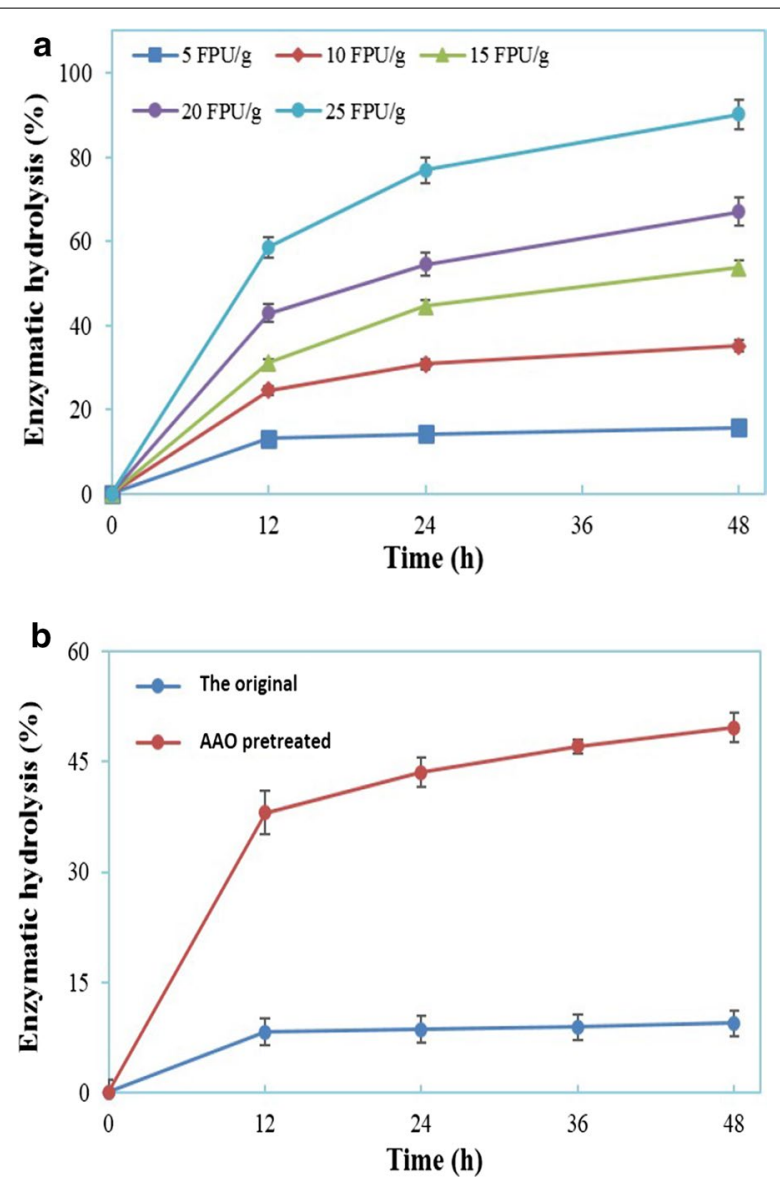

Fig. 2 Evaluation of the hydrolyzability of AAO-pretreated substrates. a Effect of different enzyme loadings (FPU/g DM) on the enzyme hydrolysis of substrates ( $2 \%$ solid content); b enzyme hydrolysis ( $5 \%$ solid content, $15 \mathrm{FPU} / \mathrm{g}$ DM) of substrates before and after the AAO pretreatment

Nevertheless, the hydrolyzability of AAO-pretreated TOFH was still limited, far away from the industrial interest, as the high enzymatic hydrolysis was with sacrifice of high enzyme loading. As for the AAO-pretreated substrate, it still had such a high lignin content up to $25 \%$ that the lignin could impede the enzymatic hydrolyzability of substrates to some extent. Additionally, acetylization of the cellulose, occurring commonly during the AAO pretreatment, was very probably adverse to the enzymatic hydrolysis of substrates [10, 25]. Therefore, a second-step AHP pretreatment was implemented to improve the enzymatic hydrolysis with a low cellulase loading.

\section{AHP pretreatment for the further delignification}

During the AHP pretreatment process, $\mathrm{H}_{2} \mathrm{O}_{2}$ concentration was selected as the key variable under some fixed conditions (12.5\% solid content, $\mathrm{pH} 11.5$ and ambient temperature), since delignification is strongly $\mathrm{pH}$ dependent. AHP pretreatment was evaluated at different $\mathrm{H}_{2} \mathrm{O}_{2}$ concentrations, as shown in Fig. 3. Initially, the pretreatment yield reduced obviously at a high $\mathrm{H}_{2} \mathrm{O}_{2}$ concentration, owing to delignification. As a result, cellulose content of AHP-pretreated substrate increased significantly. At $3 \%$ of $\mathrm{H}_{2} \mathrm{O}_{2}$, the substrate had a high cellulose content with almost a minimum lignin residual, accounting for 65 and $10 \%$ of the substrate composition, respectively. Thereafter, the lignin removal increased marginally and thus contributed to a slight increase of cellulose content. Consequently, $3 \% \mathrm{H}_{2} \mathrm{O}_{2}$ was selected for the optimal addition for the AHP pretreatment. Meanwhile, the cellulose retention and the delignification reached 98 and $74 \%$, respectively. And the AAO-AHP-pretreated substrate is cellulose-enriched, consisting of $65 \%$ cellulose, $15 \%$ hemicellulose, and 10\% lignin. The data indicated that the AHP pretreatment, commonly used as a postpretreatment, had an outstanding capability of selective delignification. This is in agreement with the literature [14-16, 18].

As for the AAO-AHP pretreatment, the lignin and hemicellulose removal was 92 and $88 \%$, respectively, with $87 \%$ of the cellulose retention. The result is extremely competitive to other studies published on the uncommon feedstock and mild AAO-/AHP-based pretreatment. As shown in Table 3, some lignocellulosic feedstocks, i.e., C. inophyllum shell and E. ulmoides Oliver have gained much research interest $[15,26]$. Like these uncommon lignocellulosic materials, TOFH is applicable as a valueadded lignocellulosic feedstock for the future biofuel production. In most case, the single AAO pretreatment with acid catalysis is not satisfactory as expected because of the limited delignification and cellulose acetylization $[9,10,23]$. In our study, the AAO pretreatment removed $70 \%$ lignin from $\mathrm{TOFH}$, contributing the residual lignin to $26 \%$ of the pretreated substrate. Thus, a subsequent post-pretreatment is desirable for further delignification to release more fermentable sugars. AHP has been confirmed to be a very effective post-pretreatment by dozens of researchers [15, 27]. Zhu et al. [15] studied the AHP pretreatment $\left(1.5 \% \mathrm{H}_{2} \mathrm{O}_{2}, \mathrm{pH} 11.5\right)$ of steam exploded $E$. ulmoides Oliver and achieved a good delignification of 92\%. An $\mathrm{AAO}-\mathrm{NH}_{3} \cdot \mathrm{H}_{2} \mathrm{O}$ combination process developed by Kim et al. [22] supplied a guideline to find new pretreatment, though presenting a limited component selectivity (60\% delignification and $67 \%$ cellulose retention) on empty fruit bunches probably due to the low solvent concentration. At contrast, Snelders et al. [18] contributed to $96 \%$ delignification and $93 \%$ cellulose retention in the wheat straw by using a formic/acetic acid $-\mathrm{H}_{2} \mathrm{O}_{2}$ pretreatment, indicating of a robust pretreatment selectivity. 


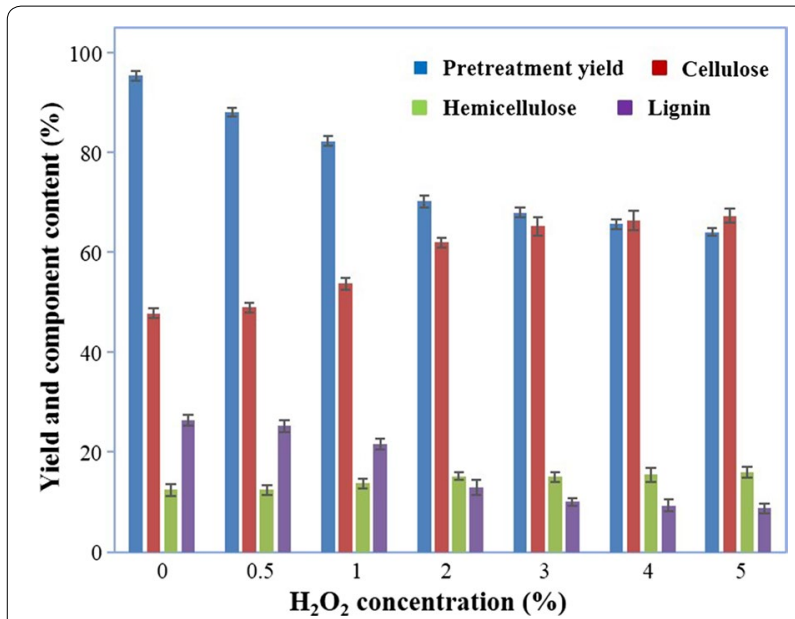

Fig. 3 Selection of $\mathrm{H}_{2} \mathrm{O}_{2}$ concentration ( $v / v$ on the solution) for the AHP pretreatment. The pretreatment was carried out for $12 \mathrm{~h}$ at a fixed condition ( $\mathrm{pH} 11.5,25^{\circ} \mathrm{C}, 12.5 \%$ solid content, 150 rpm shaking speed). The percentages of yield and component content refer to the weights of AAO-pretreated substrates and AHP-pretreated substrates, respectively

The AAO-AHP pretreatment developed herein removed 92\% lignin and $88 \%$ hemicellulose from the TOFH, simultaneously with $87 \%$ cellulose retention. The pretreatment produced a cellulose-rich (65\%) substrate with a low lignin content $(10 \%)$. It was confirmed that the AAOAHP pretreatment was effective in selectively pretreating the lignocellulosic biomass. In our recent publication on AGO pretreatment of TOFH, the AGO-pretreated substrate had a low cellulose content of $22 \%$ and high lignin content of 27\% [7]. Comparing the AGO pretreatment, the AAO-AHP pretreatment developed herein has presented a good advantage over it.

\section{Enzymatic hydrolysis of substrates after AAO-AHP pretreatment}

Enzymatic hydrolysis of AAO-AHP-pretreated substrates was implemented at $5 \%$ solid content for $48 \mathrm{~h}$ to evaluate the hydrolyzability. As shown in Fig. 4, the substrate achieved an almost complete hydrolysis at $10 \mathrm{FPU} / \mathrm{g}$ DM. The 48-h enzymatic hydrolysis of substrates was 85 and $94 \%$ at 3 and $5 \mathrm{FPU} / \mathrm{g}$, respectively. This was much higher as compared to that of the AAOpretreated substrates, in that the latter was only $20 \%$ of the enzymatic hydrolysis at $5 \mathrm{FPU} / \mathrm{g}$ DM with $2 \%$ solid content. Based on the above chemical composition, it can be judged that the increase of enzymatic hydrolysis originated from the further delignification made by AHP pretreatment. Additionally, the AHP pretreatment can effectively remove acetyl groups formed with acetic acid acetylizing the cellulose during the above AAO

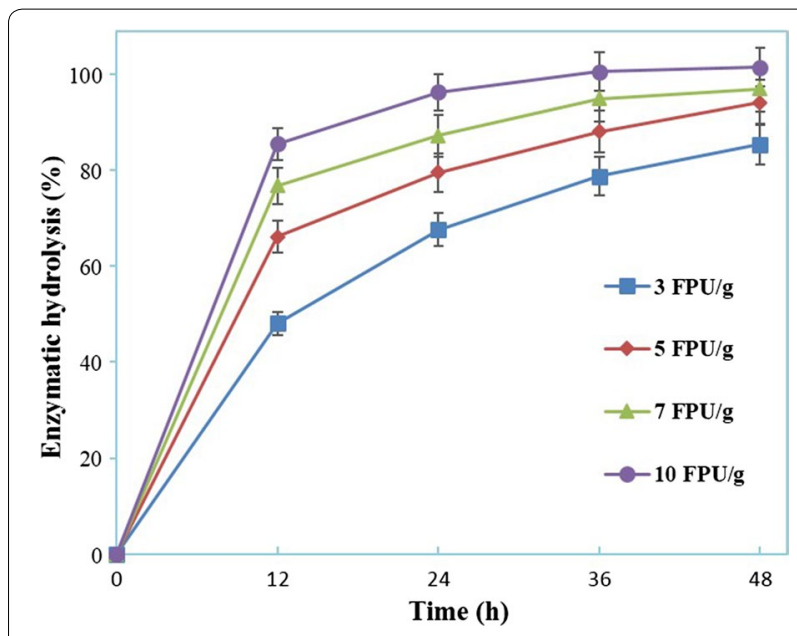

Fig. 4 Enzymatic hydrolysis of AAO-AHP-pretreated substrates at different enzyme loadings (FPU/g DM). The hydrolysis was carried out at $\mathrm{pH} 4.8,50^{\circ} \mathrm{C}$ for $48 \mathrm{~h}$ with $5 \%$ solid content $(\mathrm{w} / \mathrm{w})$

pretreatment, which is at least partly responsible for the improved hydrolyzability [10].

The hydrolyzability of AAO-AHP-pretreated substrates was compared with that reported on other uncommon lignocellulosic biomass and on other AAO-/ AHP-based pretreatment (Table 4). Like other lignocellulosic substrate, the hydrolyzability of the original TOFH is very poor, hence a low enzymatic hydrolysis even with a high cellulase loading, because of the recalcitrant structure [26, 28, 29]. The substrates undergoing AAO-/AHP-based pretreatment have presented an improved hydrolyzability to a different extent depending on the substrate variety, pretreatment process, hydrolytic enzymes, and hydrolytic conditions [14, 15, 22, 26]. It is evident that the AAO-AHP-pretreated TOFH substrate is competitive to these substrates at the hydrolyzability.

As for the pretreatment, all these methods can allow the substrate for hydrolyzability increase with varying degrees [10, 21, 27, 30]. Notably, Li et al. [16] reported $71 \%$ of enzymatic hydrolysis at an industrially relevant enzyme loading (3 FPU/g substrate) when evaluating the hydrolyzability of dilute $\mathrm{HCl}-\mathrm{H}_{2} \mathrm{O}_{2}$-pretreated corn stover. In this study, the enzymatic hydrolysis of TOFH subjected to AAO-AHP pretreatment reached $85 \%$ at 3 FPU/g of cellulase preparation Cellic CTec2. Such low enzyme loading has been considered to be very economic at present enzyme costs [16]. Compared with the AGOpretreated TOFH reported by us just recently [7], the enzyme loading on AAO-AHP-pretreated substrates was only $15 \%$ that of it (20 FPU/g) to reach almost equivalent enzymatic hydrolysis. Accordingly, it is certain that the hydrolyzability of AAO-AHP-pretreated TOFH feedstock is robust. TOFH, as a main byproduct of tea oil 
Table 4 Hydrolyzability of various substrates

\begin{tabular}{|c|c|c|c|c|c|c|c|}
\hline \multicolumn{2}{|l|}{ Substrate } & \multicolumn{4}{|c|}{ Hydrolytic condition } & \multirow[t]{3}{*}{ Enzymatic hydrolysis (\%) } & \multirow[t]{3}{*}{ Source } \\
\hline \multirow[t]{2}{*}{ Variety } & \multirow[t]{2}{*}{ Pretreatment type } & \multirow{2}{*}{$\begin{array}{l}\text { Solid } \\
\%\end{array}$} & \multicolumn{2}{|l|}{ Cellulase } & \multirow{2}{*}{$\begin{array}{l}\text { Time } \\
\mathbf{h}\end{array}$} & & \\
\hline & & & Variety (FPU/g) & Loading & & & \\
\hline C. inophyllum shell & $\mathrm{H}_{2} \mathrm{SO}_{4}+\mathrm{NaOH}$ & 10 & Accellerase $^{\mathrm{TM}} 1500$ & - & 72 & 50 (RS) & Cheng et al. [26] \\
\hline Bamboo shoot hull & $9 \% \mathrm{Na}_{3} \mathrm{PO}_{4}+3 \% \mathrm{H}_{2} \mathrm{O}_{2}$ & 1 & Accellerase $^{\mathrm{TM}} 1500$ & 30 & 72 & 86 (RS) & Qing et al. [14] \\
\hline EFB & $\mathrm{AAO}-\mathrm{AQA}$ & 2 & Cellulase $1.5 \mathrm{~L}$ & 15 & 96 & 73 & Kim et al. [22] \\
\hline E. ulmoides Oliver & $\mathrm{SEP}+\mathrm{AHP}$ & 5 & Youtell cellulase & 20 & 96 & $83(\mathrm{G})$ & Zhu et al. [15] \\
\hline Cashew apple bagasse & $4.3 \% \mathrm{AHP}$ & 9 & Novozymes cellulase & 15 & 72 & $86(\mathrm{G})$ & da Costa et al. [13] \\
\hline Lespedeza stalk & $\mathrm{SEP}+\mathrm{AHP}$ & 5 & Cellulase $1.5 \mathrm{~L}$ & 12.4 & 96 & $89(\mathrm{G})$ & Su et al. [27] \\
\hline Sugarcane bagasse & $\mathrm{AAO}$ & 2.5 & Cellulase $1.5 \mathrm{~L}$ & 20 & 120 & 63 (RS) & Zhao et al. [10] \\
\hline Corn stover & $3 \% \mathrm{H}_{2} \mathrm{O}_{2}+7.5 \mathrm{~g} / \mathrm{L} \mathrm{NaOH}$ & 6 & Spezyme CP & 30 & 72 & $35(G)$ & He et al. [21] \\
\hline Corn stover & $\mathrm{HCl}+\mathrm{H}_{2} \mathrm{O}_{2}$ & 5 & Novozymes cellulase & 3 & 72 & $71(\mathrm{G})$ & Li et al. [16] \\
\hline Sugarcane bagasse & $2 \% \mathrm{H}_{2} \mathrm{SO}_{4}+4.7 \% \mathrm{H}_{2} \mathrm{O}_{2}$ & 10 & Celluclast $1.5 \mathrm{~L}$ & 4.1 & 120 & $65(\mathrm{G})$ & Morando et al. [17] \\
\hline TOFH & None & 5 & GC220 & 50 & 48 & 39 (RS) & Sun et al. [7] \\
\hline TOFH & AGO & 5 & GC220 & 20 & 48 & 80 (RS) & Sun et al. [7] \\
\hline TOFH & $\mathrm{AAO}$ & 5 & Cellic CTec2 & 15 & 48 & 50 (RS) & This paper \\
\hline TOFH & $\mathrm{AAO}+\mathrm{AHP}$ & 5 & Cellic CTec2 & 3 & 48 & 85 (RS) & This paper \\
\hline
\end{tabular}

$E F B$ empty fruit bunches, SEP steam explosion pretreatment, $A Q A$ aqueous ammonia, $G$ glucose, $R S$ reducing sugars

processing industry, is applicable for the current biofuel production. The AAO-AHP combination pretreatment can be a promising candidate for bioprocessing of lignocellulosic biomass.

\section{Structural features of AAO and AAO-AHP-pretreated substrates}

Many researchers have argued that the main chemical composition (cellulose, lignin, and hemicellulose) and physical structure (surface area, average size, and the crystallinity) of lignocellulose biomass are available to represent the inherent recalcitrance of substrate to enzymatic hydrolysis [29, 31-33]. Consequently, structural features of substrates at different pretreatment stages were depicted in the ensuing work.

\section{SEM analysis}

As for exploring the physical feature of AAO and AAOAHP-pretreated substrates in favor of enzymatic hydrolyzability, some morphological changes of feedstock with different pretreatments were determined with a series of comparative SEM observations (Additional file 1: Figure S2). The AEO undissolved feedstock exposed the inner structure of lignocellulose presenting more bunchy fiber and curly surface clumps. With the two-stage pretreatment, a significant size reduction of lignocellulose occurred. On the surface of AAO-pretreated substrates, there existed so many holes, very probably due to the AAO penetration and solvolytic reaction during the pretreatment, which increased the specific surface area of substrates and facilitated the accessibility to cellulase enzymes. After the AHP pretreatment, the perforated surface was further disrupted in some small fragments with a more roughness and surface area. These images indicate that the pretreatment has gradually dissected the physically structural barrier of substrates and led to a large portion of long defibrillated fibrils, making the cellulose more exposed with more surface area and roughness. Consequently, the surface feature of two-stage pretreated substrates is extremely accessible and susceptible to cellulase enzymes, hence to a high enzymatic hydrolysis yield [14, 33-35]. Therefore, these observations partly explain why the pretreatment can effectively improve the enzymatic hydrolyzability of the TOFH.

\section{CLSM analysis}

Considering the lignin is a complex heteropolymer with strong autofluorescence in the visible and far-IR regions, the CLSM was used to visualize the structure on the lignin distribution, cell wall transverse dimensions, and fiber surfaces [32, 33]. Figure 5 illustrates the CLSM images of substance undergoing the AAO pretreatment in combination with alkaline $\mathrm{H}_{2} \mathrm{O}_{2}$. The AEO undissolved feedstock had an intact structure with the ligninrich sclerenchyma and middle lamella. After the AAO pretreatment, the initial intact structure was disrupted. The primary and secondary cell walls were separated from the middle lamella, resulting in a clear distortion of the whole lignocellulosic structure at a tissue and organ level. These visualized phenomena are highlighted with 

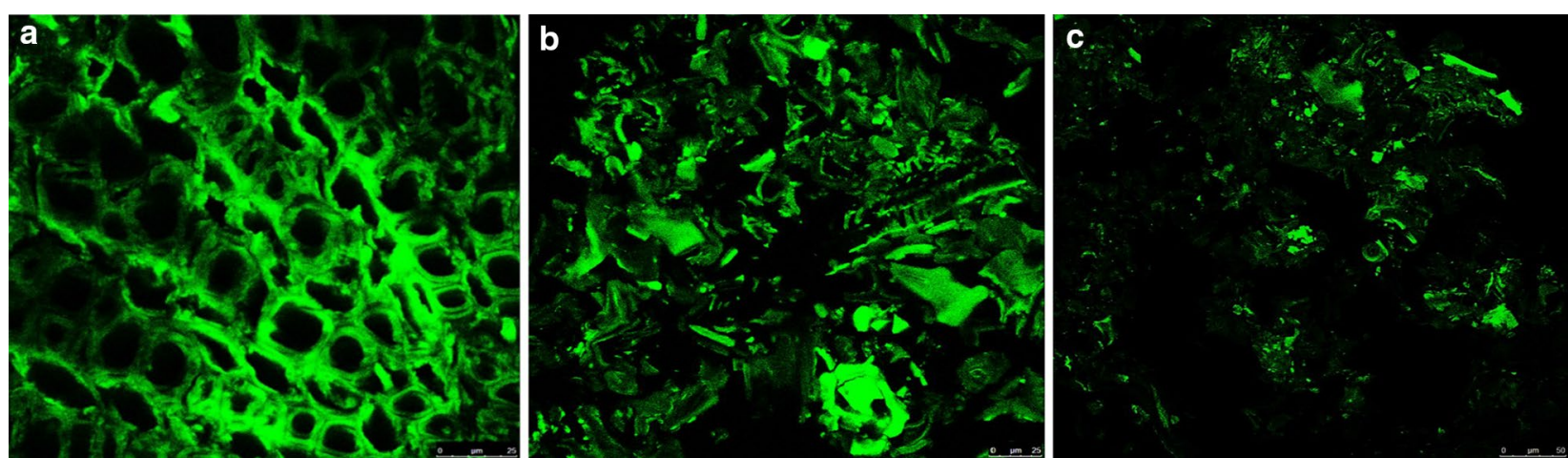

Fig. 5 CLSM images of material before and after the AAO and AAO-AHP pretreatment. Scale bar $25 \mu \mathrm{m}$. a-c means the original, AAO-pretreated and AAO-AHP-pretreated substance, respectively

the subsequent AHP pretreatment. With the AAO-AHP pretreatment, the sclerenchyma and middle lamella disintegrated, and the distorted structure was broken into more fine fragments with a more roughness and surface area. The observation is in accordance with the above SEM images.

Additionally, the brightness of fluorescence that means lignin distribution became weak with the pretreatment process. After the AAO-AHP pretreatment, many ultrastructures of substrates were invisible with too low lignin distribution. The observation was consistent with the above analysis of component contents.

\section{XRD analysis}

As shown in Additional file 1: Figure S3, X-ray diffraction curves of the feedstock before and after two-stage pretreatment were used to monitor the crystallinity. The XRD pattern had three typical peaks of cellulose, at $16^{\circ}$ $(10 \overline{1}), 21.9^{\circ}(002)$, and $34.6^{\circ}(040)$. [36]. With the AAOAHP pretreatment, the position (002) of crystal face diffraction peak shifted to the right obviously, while the other two $(10 \overline{1}, 040)$ kept stable. And the peaks of the crystal surface at the position $(10 \overline{1}, 002)$ intensified significantly. The result inferred these pretreatments had a remarkable influence on the crystalline cellulose, at least causing an increase in crystalline cellulose content. To verify it, the crystallinity index (CrI) and crystallite size of samples were detected (Additional file 1: Table S7). The CrI was $21.3 \%$ in the original feedstock. It augmented to 41.3 and $52.1 \%$, respectively, with the AAO and AAO-AHP pretreatment. This relative increase indicates that the removal of amorphous components such as lignin and hemicelluloses (resulting in an increase of CrI) outplayed the swelling and dissolution of the cellulose (a reduction of CrI) [31,33]. As for the crystallite size, the average size of the original cellulose crystallite was $1.5 \mathrm{~nm}(002)$. Notably, it became big slightly after the
AAO pretreatment. And the average size increased twice with the AHP pretreatment. It is apparent that the pretreatment resulted in a big size of crystalline cellulose. The result is beyond the expectation and inconsistent with previous results that the pretreatment can dissociate the crystalline cellulose into some small sizes [33, 37]. This finding is so abnormal that scare information is responsible for it [36]. Based on the significant peak (002) shift from $21.1^{\circ}$ to $22.5^{\circ}$, it can be guessed that re-formation or recrystallization of crystalline cellulose possibly occurred during the AHP pretreatment [31-33].

Based on the above structural observation, it is revealed that the AAO-AHP pretreatment can contribute to the great modification of lignocellulosic biomass at surface area, average size, components redistribution to a good enzymatic hydrolysis.

\section{Mass balance analysis}

The analysis presents an entire workflow on the twostage fractionation of TOFH. As shown in Fig. 6, 70\% of the lignin and $86 \%$ of the hemicellulose removed from the original feedstock with AAO pretreatment. The AAO-pretreated substrate mainly consisted of $44 \%$ cellulose, $12 \%$ hemicellulose, and $25 \%$ lignin. Furthermore, the AHP pretreatment enabled the lignocellulosic substrate to a deep delignification selectively, contributing to $75 \%$ of the lignin removal with an almost intact cellulose retainment. In other words, the AAO-AHP pretreatment has extracted $92 \%$ of the lignin and $88 \%$ of the hemicelluloses from the original feedstock, with $87 \%$ the cellulose retention. As a result, the feedstock undergoing the two-stage pretreatment is typical of rich cellulose content (65\%). Accordingly, the TOFH is a desirable feedstock applicable for bioprocessing of the renewable biomass like other common lignocellulosic biomass. The AAO-AHP pretreatment process constructed herein has 


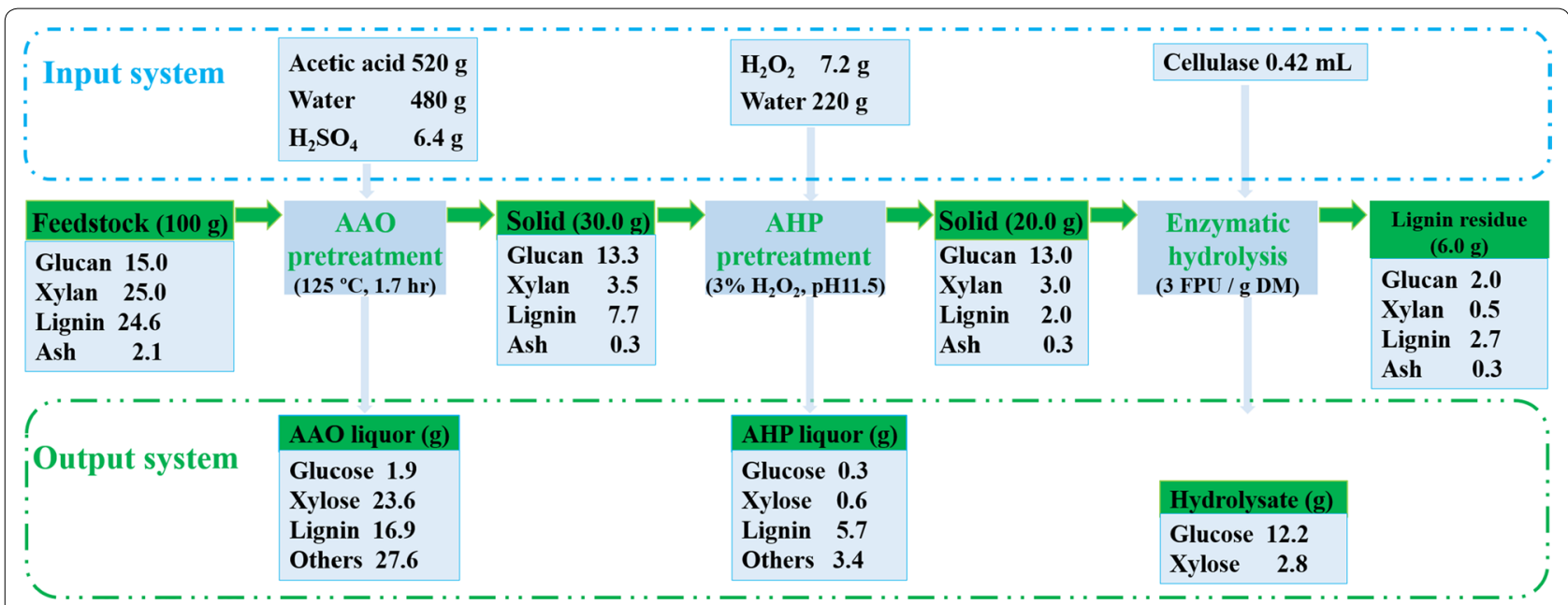

Fig. 6 Mass balance of the AAO-AHP pretreatment of TOFH

presented an outstanding feature of good selectivity on the TOFH feedstock.

AAO-AHP-pretreated substrates have presented appealing structural features, i.e., big specific area and low lignin contribution, towards a good susceptibility and accessibility to cellulase enzymes. Thus, the substrate has presented a superior hydrolyzability, with enzymatic hydrolysis attaining at $85 \%$ at $3 \mathrm{FPU} / \mathrm{g} \mathrm{DM}$ for $48 \mathrm{~h}$. To our knowledge, there is rare information reported on such the good hydrolyzability. Accordingly, the hydrolyzability of AAO-AHP-pretreated substrates is at a relatively good level, which is attractive for the current lignocellulosic biomass refining industry. The AAO-AHP pretreatment possesses a superior advantage at modifying the structure and improving the hydrolyzability of substrates.

During the AAO pretreatment, components amounting to $70 \%$ of the original feedstock were dissolved into the pretreatment liquor. Besides the known substances (xylose, lignin, and glucose), other undetected components presumably involved xylan, glucan, lipid, tea saponin, and pectin in the AAO pretreatment liquor [6, 7]. Hereinto, several studies have showed the separation process of lignin and hemicellulose in the AAO pretreatment liquor [8]. Hence, the lignin and hemicelluloses are of big promise to separate from the pretreatment liquor for use $[15,38]$. In the next work, accordingly, the separation of these dissolved components would be attached to importance for the value-added utilization.

\section{Conclusions}

The TOFH, a main byproduct of tea oil processing industry is promisingly applicable as renewable lignocellulosic feedstock. The AAO-AHP pretreatment has presented an outstanding feature in selective fractionation of the lignocellulosic biomass, extremely effective to improve the substrate hydrolyzability. The AAO-AHP pretreatment can be a desirable candidate for the current pretreatment.

\section{Methods}

Materials

The TOFH was supplied by National Camellia Project Technology Research Center in Changsha, Hunan Province, China. Before the AAO pretreatment, the TOFH was milled and treated with aqueous ethanol for extraction of the tea saponin and tannin according to our previous method [7]. The AEO-extracted TOFH was air-dried (6\% of moisture) and used as the original feedstock, containing $15.0 \%$ cellulose, $25.0 \%$ hemicellulose, and $24.6 \%$ lignin in this study. Commercial cellulase preparation, Cellic CTec2 (150 FPU/mL) was presented by Novozymes (China) Investment Co. Ltd.

\section{Experimental methods AAO pretreatment}

The pretreatment was conducted in a reactor comprising an air bath incubator, a centrifugal rotation with eight stands and eight vessels (Keli Automation, Yantai City, China). The vessel was manufactured from stainless steel (SUS 316) and had a capacity of $200 \mathrm{~mL}$. In the experiment, the air-dried substrate of $10.5 \mathrm{~g}$ was mixed with acetic acid solution of $100 \mathrm{~mL}$ in the vessel, in which sulfuric acid was added as a catalyst [8]. The vessel was air-heated at a fixed temperature for some time under the closure condition. At the end of the holding time, the vessel was pulled out of the air bath incubator and put in an ice-water bath to cool down. Then, the reaction 
mixture was separated by filtration through $\mathrm{G}_{3}$ glass filter $(100 \mathrm{~mL}$, pore size $15-40 \mu \mathrm{m})$ and washed twice with $400 \mathrm{~g}(50 \%)$ aqueous acetic acid [9]. After wash with distilled water twice ( $200 \mathrm{~g} /$ wash), the insoluble solid fraction was divided into two parts. One part was conserved in a sealed bag at $4{ }^{\circ} \mathrm{C}$ for the further enzymatic hydrolysis, and the other was dried at $105{ }^{\circ} \mathrm{C}$ to determine the pretreatment yield, main composition, and structural feature. Experiment with each sample was performed in duplicate, with the average value reported. The standard deviation is $<3 \%$.

\section{Optimization of $A A O$ pretreatment}

Given the influence of such variables as pretreatment temperature, pretreatment time, acetic acid concentration $(\mathrm{v} / \mathrm{v})$, and $\mathrm{H}_{2} \mathrm{SO}_{4}$ addition $(\mathrm{w} / \mathrm{v})$, the AAO pretreatment was optimized with a series of experiments of a Plackett-Burman design (PBD), a steepest ascent design and a central composite design $[39,40]$. The most prominent parameters and the optimal concentrations domain were tested using a Plackett-Burman design (Additional file 1: Table S1) and a steepest ascent experiment, respectively. For the central composite design experiments of three factors, there were 14 experiments augmented and six replications at the center values (zero level) to evaluate the pure error, as shown in Additional file 1: Tables S3 and S4.

Using the software Design Expert-8.0, the response surface model was obtained and confirmed for a secondorder model by statistical analysis. Statistical analysis of the model was performed to evaluate the analysis of variance (ANOVA). The quality of the polynomial model equation was judged statistically using the coefficient of determination $R^{2}$ and adjustment $R^{2}$, and its statistical significance was determined by $F$ value and $P$ value. The significance of the regression coefficients was tested by some parameters, such as coefficient of variation $(\mathrm{CV})$ and adequate precision.

\section{AHP pretreatment}

Undissolved solid fraction after the AAO pretreatment, namely AAO-pretreated substrate was followed by AHP pretreatment. In the study, the $\mathrm{H}_{2} \mathrm{O}_{2}$ solution was adjusted to $\mathrm{pH} 11.5$ using $\mathrm{NaOH}[13,17]$. The AHP pretreatment was conducted with $12.5 \%$ of the solid content in an incubator for $12 \mathrm{~h}$ at room temperature. Under controlled condition, an optimal AHP concentration was selected at $0-5 \%(\mathrm{v} / \mathrm{v})[14,16]$. After the AHP pretreatment, the solid and liquid fractions were separated by filtration as the above AAO pretreatment. The solid fractions were washed until neutral with the hot water $\left(60{ }^{\circ} \mathrm{C}\right)$, and then dried at $60^{\circ} \mathrm{C}$ overnight for subsequent study. All experiments were performed in duplicate under the same condition and average values are reported. The standard deviation is $<3 \%$.

\section{Enzymatic hydrolysis}

Each individual sample, approximately $0.5 \mathrm{~g}$ dry weight, of AEO, AAO, and AAO-AHP-pretreated substrates, was put into a $100 \mathrm{~mL}$ flask and suspended quickly with $25 \mathrm{~mL}(10 \mathrm{~mL})$ citric buffer $(0.05 \mathrm{M}, \mathrm{pH} 4.8)$ to acquire the slurry with $2 \%(5 \%)$ solids content (w/v) [33, 41]. The slurry was then supplemented with the cellulase preparation Cellic CTec2 at some enzyme loadings (FPU/g dry mass). The enzymatic hydrolysis was performed in an incubator $\left(50{ }^{\circ} \mathrm{C}, 150 \mathrm{rpm}\right)$ for $48 \mathrm{~h}$. And the enzymatic hydrolysis (\%) would be used to evaluate the hydrolyzability of various materials. Experiment with each sample was performed in duplicate, with the average value reported. The standard deviation is $<3 \%$.

\section{Characterization on the structural feature of substrates}

Before the analysis, all the wet samples from AAO and AAO-AHP pretreatment were parted manually into small fragments and dried to a constant weight at $60{ }^{\circ} \mathrm{C}$. Changes in morphology of the samples were observed with a scanning electronic microscopy (SEM) (Quznfa-200, FEI, Netherlands) operated at $10 \mathrm{kV}$ acceleration voltages. Morphological change of the sample was further observed with a confocal laser scanning microscopy (CLSM) (LSM 710, Zeiss, Germany) [7]. Sections of the tissue were observed directly by autofluorescence without staining. Thirty-two scans were taken for each sample with a resolution of $2 \mathrm{~cm}^{-1}$ in the transmission mode. X-ray diffraction (XRD) pattern of the sample was carried out on a D8 (AXS, Germany) $\mathrm{X}$-ray diffractometer equipped with $\mathrm{Ni}$-filtered $\mathrm{Cu} \mathrm{K \alpha} \alpha_{1}$ radiation $(\lambda=0.154 \mathrm{~nm})$ at room temperature [33]. The crystallinity index (CrI) of samples was calculated. The average size of crystallite was evaluated according to the Scherrer equation.

\section{Analytical procedures}

Cellulase activity was determined by filter paper activity. The total reducing sugars were determined by the standard DNS method. The hydrolyzability was evaluated as follows: enzymatic hydrolysis $(\%)=100 \times 0.9 \times(\mathrm{g}$ in reducing sugar $) \times(\mathrm{g} \text { in carbohydrates })^{-1}$. The carbohydrate and lignin content in the sample was determined by a two-step acid hydrolysis method (NREL) [42]. The Chromaster HITACHI HPLC system equipped with an Aminex HPX-87H column $(300 \mathrm{~mm} \times 7.8 \mathrm{~mm}$, Bio- Rad, US) and the RI detector was used to detect glucose and xylose at $60{ }^{\circ} \mathrm{C}$ of the column temperature, with $5 \mathrm{mM}$ $\mathrm{H}_{2} \mathrm{SO}_{4}$ as the mobile phase at a flow rate of $0.6 \mathrm{~mL} / \mathrm{min}$. The pretreatment yield $(\%)=100 \times(\mathrm{g}$ of pretreated 
solid $) \times(\mathrm{g} \text { of feedstock })^{-1}$. The cellulose retention $(\%)=100 \times(\mathrm{g}$ in cellulose of pretreated solid $) \times(\mathrm{g}$ in cellulose of feedstock) ${ }^{-1}$. The component (hemicellulose/ lignin) removal $(\%)=100-100 \times(\mathrm{g}$ in component of pretreated solid $) \times(\mathrm{g} \text { in component of feedstock })^{-1}$. All experiments were performed in duplicate under the same condition and average values are reported. The standard deviations are $<2 \%$.

\section{Additional file}

Additional file 1: Table S1. PBD experimental design of the AAO pretreatment. Table S2. Analysis of PBD design on optimization of each variable. Table S3. Experimental range and levels of independent variables. Table S4. Full factorial CCD matrix of three variables in coded units and the experimentally observed response. Table S5. ANOVA results for the quadratic equation for the delignification. Table S6. Model coefficient estimated by multiple linear regression for the delignification. Table S7. Crystalline of the lignocellulosic biomass before and after the two-stage pretreatment. Figure S1. Predicted values versus experimental values of CCD on the delignification. Figure S2. SEM images of material before and after the $A A O$ and $A A O-A H P$ pretreatment. $A, B$ and $C$ means the original, AAO pretreated and AAO-AHP pretreated substance, respectively. Figure S3. X-ray diffraction patterns of the substance before and after the AAO and AAO-AHP pretreatment.

\section{Abbreviations}

TOFH: tea oil fruit hull; AEO: aqueous ethanol organosolv; AGO: atmospheric glycerol organosolv; AAO: acetic acid organosolv; AHP: alkaline hydrogen peroxide; NREL: national renewable energy laboratory; DM: dry mass; FPU: filter paper unit; PBD: Plackett-Burman design; ANOVA: analysis of variance; CCD: central composite design; CV: coefficient of variation; SEM: scanning electron microscopy; CLSM: confocal laser scanning microscopy; XRD: X-ray diffraction; Crl: crystallinity index; EFB: empty fruit bunches; SEP: steam explosion pretreatment; AQA: aqueous ammonia; FA: formic acid; G: glucose; RS: reducing sugars.

\section{Authors' contributions}

FFS and $\mathrm{HL}$ designed the project, supervised the experiments, interpreted the data, and prepared the manuscript. ST, RL, and RW conducted the experiment on the fractionation. CD and ZG helped the pretreatment. $Z Z, Z X$, and CL contributed to the experimental design and helped polish it. All authors read and approved the final manuscript.

\section{Author details}

${ }^{1}$ Key Laboratory of Carbohydrate Chemistry and Biotechnology, Ministry of Education, School of Biotechnology, Jiangnan University, Wuxi 214122, China. ${ }^{2}$ State Key Laboratory of Pulp and Paper Engineering, South China University of Technology, Guangzhou 510640, China. ${ }^{3}$ National Engineering Research Center for Oil-tea Camellia, Hunan Academy of Forestry, Changsha 410004, China. ${ }^{4}$ Key Laboratory of Advanced Textile Materials and Manufacturing Technology, Ministry of Education, Zhejiang Sci-Tech University, Hangzhou 310018, China. ${ }^{5}$ Centre for Tropical Crops and Biocommodities, Queensland University of Technology, Brisbane QLD 4001, Australia.

\section{Acknowledgements}

Authors give thanks to the Priority Academic Program Development of Jiangsu Higher Education Institutions, the 111 Project (No. 111-2-06), and the Jiangsu province "Collaborative Innovation Center for Advanced Industrial Fermentation" industry development program.

\section{Competing interests}

The authors declare that they have no competing interests.

\section{Availability of supporting data}

All relevant data have been included in this published article and its Additional file 1.

\section{Consent for publication}

All the authors approved the manuscript.

\section{Funding}

The main work was supported from the Opening Project of National Engineering Research Center for Oil-tea Camellia (2014CY01) and the National Natural Science Foundation of China (21176106; 21407046). Part of the support was from and Fundamental Research Funds for the Central Universities (JUSRP51635B), State Key Laboratory of Pulp and Paper Engineering (201513), and Key Laboratory of Advanced Textile Materials and Manufacturing Technology (2015002).

\section{Publisher's Note}

Springer Nature remains neutral with regard to jurisdictional claims in published maps and institutional affiliations.

Received: 15 February 2017 Accepted: 5 April 2017

Published online: 08 April 2017

\section{References}

1. Huang J, Ahrends A, He J, Gui H, Xu J, Mortimer P. An evaluation of the factors influencing seed oil production in Camellia reticulata L. plants. Ind Crop Prod. 2013;50:797-802.

2. Lee CP, Yen GC. Antioxidant activity and bioactive compounds of tea seed (Camellia Oleifera Abel.) oil. J Agric Food Chem. 2006;54:779-84.

3. Jian HL, Liao XX, Zhu LW, Zhang WM, Jiang JX. Synergism and foaming properties in binary mixtures of a biosurfactant derived from Camellia oleifera Abel. and synthetic surfactants. J Colloid Interface Sci. 2011;359:487-92.

4. Su MH, Shih MC, Lin KH. Chemical composition of seed oils in native Taiwanese Camellia species. Food Chem. 2014;156:369-73.

5. Zhou H, Wang CZ, Ye JZ, Chen HX. New triterpene saponins from the seed cake of Camellia Oleifera and their cytotoxic activity. Phytochem Lett. 2014;8:46-51.

6. Jin XC. Bioactivities of water-soluble polysaccharides from fruit shell of Camellia oleifera Abel.: antitumor and antioxidant activities. Carbohydr Polym. 2012;87:2198-201.

7. Sun FB, Tang S, Liu RK, Tang YJ, Wang R, Zhang ZY, Gao ZY, Xiao ZH. Biorefining fractionation of the Camellia oleifera Abel. hull into diverse bioproducts with a two-stage organosolv extraction. Ind Crop Prod. 2016;94:790-9.

8. Pan XJ, Sano Y. Acetic acid pulping of wheat straw under atmospheric pressure. J Wood Sci. 1999;45:319-25.

9. Pan XJ, Sano Y. Fractionation of wheat straw by atmospheric acetic acid process. Bioresour Technol. 2005;96:1256-63.

10. Zhao X, Morikawa Y, Qi F, Zeng J, Liu D. A novel kinetic model for polysaccharide dissolution during atmospheric acetic acid pretreatment of sugarcane bagasse. Bioresour Technol. 2014;151:128-36.

11. Sun SN, Sun SL, Cao XF, Sun RC. The role of pretreatment in improving the enzymatic hydrolysis of lignocellulosic materials. Bioresour Technol. 2015;199:49-58.

12. Li MF, Yang S, Sun RC. Recent advances in alcohol and organic acid fractionation of lignocellulosic biomass. Bioresour Technol. 2016;200:971-80.

13. da Costa JA, Marques JE Jr, Gonçalves LRB, Rocha MVP. Enhanced enzymatic hydrolysis and ethanol production from cashew apple bagasse pretreated with alkaline hydrogen peroxide. Bioresour Technol. 2015;179:249-59.

14. Qing Q, Zhou L, Huang M, Guo Q, He Y, Wang L, Zhang Y. Improving enzymatic saccharification of bamboo shoot shell by alkalic salt pretreatment with $\mathrm{H}_{2} \mathrm{O}_{2}$. Bioresour Technol. 2016;201:230-6.

15. Zhu MQ, Wen JL, Wang ZW, Su YQ, Qin W, Sun RC. Structural changes in lignin during integrated process of steam explosion followed by alkaline 
hydrogen peroxide of Eucommia ulmoides Oliver and its effect on enzymatic hydrolysis. Appl Energy. 2015;158:233-42.

16. Li WZ, Liu QY, Ma QZ, Zhang TW, Ma LL, Jameel H, Chang HM. A twostage pretreatment process using dilute hydrochloric acid followed by Fenton oxidation to improve sugar recovery from corn stover. Bioresour Technol. 2016;219:753-6.

17. Morando LEN, Gómez CXD, Zamora LL, Uscanga MGA. Statistical optimization of alkaline hydrogen peroxide pretreatment of sugarcane bagasse for enzymatic saccharification with Tween 80 using response surface methodology. Biomass Convers Biorefin. 2014;4:15-23.

18. Snelders J, Dornez E, Benjelloun-Mlayah B, Huijgen WJ, de Wild PJ, Gosselink RJ, Gerritsma J, Courtin CM. Biorefining of wheat straw using an acetic and formic acid based organosolv fractionation process. Bioresour Technol. 2014;156:275-82.

19. Wang Q, Hu JG, Fei S, Mei ZL, Gang Y, Zhang YZ, Hu YD, Jing Z, Deng SH. Pretreating wheat straw by the concentrated phosphoric acid plus hydrogen peroxide (PHP): investigations on pretreatment conditions and structure changes. Bioresour Technol. 2016;199:245-57.

20. Liu TJ, Williams DL, Pattathil S, Li MY, Hahn MG, Hodge DB. Coupling alkaline pre-extraction with alkaline-oxidative post-treatment of corn stover to enhance enzymatic hydrolysis and fermentability. Biotechnol Biofuels. 2014:7:48.

21. He YC, Yun D, Xue YF, Yang B, Feng L, Cheng W, Zhu ZZ, Qing Q, Hao W, Cheng Z. Enhancement of enzymatic saccharification of corn stover with sequential Fenton pretreatment and dilute $\mathrm{NaOH}$ extraction. Bioresour Technol. 2015;193:324-30

22. Kim DY, Kim YS, Kim TH, Oh KK. Two-stage, acetic acid-aqueous ammonia, fractionation of empty fruit bunches for increased lignocellulosic biomass utilization. Bioresour Technol. 2016;199:121-7.

23. Saad MBW, Oliveira LRM, Cândido RG, Quintana G, Rocha GJM, Gonçalves AR. Preliminary studies on fungal treatment of sugarcane straw for organosolv pulping. Enzyme Microb Technol. 2008;43:220-5.

24. Gao Dh, Haarmeyer C, Balan V, Whitehead TA, Dale BE, Chundawat SP. Lignin triggers irreversible cellulase loss during pretreated lignocellulosic biomass saccharification. Biotechnol Biofuels. 2014;7:175.

25. Pan XJ, Gilkes N, Saddler JN. Effect of acetyl groups on enzymatic hydrolysis of cellulosic substrates. Holzforschung. 2006;60:398-401.

26. Cheng YS, Wu JH, Yeh LH. Utilization of Calophyllum inophyllum shell and kernel oil cake for reducing sugar production. Bioresour Technol. 2016;212:338-41.

27. Su ZQ, Bu LX, Zhao DQ, Sun RC, Jiang JX. Processing of Lespedeza stalks by pretreatment with low severity steam and post-treatment with alkaline peroxide. Ind Crop Prod. 2012;36:1-8.

28. He YC, Liu F, Di JH, Ding Y, Zhu ZZ, Wu YQ, Chen L, Wang C, Xue YF, Chong GG. Effective enzymatic saccharification of dilute $\mathrm{NaOH}$ extraction of chestnut shell pretreated by acidified aqueous ethylene glycol media. Ind Crop Prod. 2016;81:129-38.

29. Auxenfans T, Crônier D, Chabbert B, Paës G. Understanding the structural and chemical changes of plant biomass following steam explosion pretreatment. Biotechnol Biofuels. 2017;10:36.
30. Yuan Z, Wen Y, Kapu NS, Beatson R, Mark MD. A biorefinery scheme to fractionate bamboo into high-grade dissolving pulp and ethanol. Biotechnol Biofuels. 2017;10:38.

31. Sannigrahi P, Miller SJ, Ragauskas AJ. Effects of organosolv pretreatment and enzymatic hydrolysis on cellulose structure and crystallinity in loblolly pine. Carbohydr Res. 2010;345:965-70.

32. Chundawat SP, Donohoe BS, Da Costa Sousa L, Elder T, Agarwal UP, Lu F, Ralph J, Himmel ME, Balan V, Dale BE. Multi-scale visualization and characterization of lignocellulosic plant cell wall deconstruction during thermochemical pretreatment. Energy Environ Sci. 2011;4:973-84.

33. Sun FB, Wang L, Hong JP, Ren JL, Du FG, Hu JG, Zhang ZY, Zhou BW. The impact of glycerol organosolv pretreatment on the chemistry and enzymatic hydrolyzability of wheat straw. Bioresour Technol. 2015;187:354-61.

34. Sun $\mathrm{FB}, \mathrm{Chen} \mathrm{HZ}$. Enhanced enzymatic hydrolysis of wheat straw by aqueous glycerol pretreatment. Bioresour Technol. 2008;99:6156-61.

35. Sun FB, Zhao XQ, Hong JP, Tang YJ, Liang W, Sun HY, Xiang L, Hu JG. Industrially relevant hydrolyzability and fermentability of sugarcane bagasse improved effectively by glycerol organosolv pretreatment. Biotechnol Biofuels. 2016;9:59.

36. Gurgel LVA, Marabezi K, Ramos LA, Curvelo AADS. Characterization of depolymerized residues from extremely low acid hydrolysis (ELA) of sugarcane bagasse cellulose: effects of degree of polymerization, crystallinity and crystallite size on thermal decomposition. Ind Crop Prod. 2012;36:560-71.

37. Zhang JZ, Ma XX, Yu JL, Zhang $X$, Tan TW. The effects of four different pretreatments on enzymatic hydrolysis of sweet sorghum bagasse. Bioresour Technol. 2011;102:4585-9.

38. Sun XF, Sun RC, Tomkinson J, Baird MS. Degradation of wheat straw lignin and hemicellulosic polymers by a totally chlorine-free method. Polym Degrad Stab. 2004;83:47-57.

39. Wang J, Zhang Z, Liu H, Sun FF, Yue C, Hu J, Wang C. Construction and optimization of trans -4-hydroxy-L-proline production recombinant E. coli strain taking the glycerol as carbon source. J Chem Technol Biotechnol. 2016;91:2389-98

40. Lin L, Li X, Cui F, Zhou H, Shen X, Dong M. Transesterification of rapeseed oil to biodiesel on Cao/a-Fe hollow fiber catalyst: optimization by response surface methodology. Bioenerg Res. 2012;5:949-57.

41. Sun FB, Chen $\mathrm{HZ}$. Evaluation of enzymatic hydrolysis of wheat straw pretreated by atmospheric glycerol autocatalysis. J Chem Technol Biotechnol. 2007:82:1039-44.

42. Sluiter A, Hames B, Ruiz R, Scarlata C, Sluiter J, Templeton D, Crocker D. Carbohydrates and lignin in Biomass Laboratory Analytical Procedure (LAP). In:Tech Rep NREL/TP-510-42618; 2008.

43. Vila C, Santos V, Parajó JC. Optimization of beech wood pulping in catalyzed acetic acid media. Can J Chem Eng. 2000;78:964-73.

\section{Submit your next manuscript to BioMed Central and we will help you at every step:}

- We accept pre-submission inquiries

- Our selector tool helps you to find the most relevant journal

- We provide round the clock customer support

- Convenient online submission

- Thorough peer review

- Inclusion in PubMed and all major indexing services

- Maximum visibility for your research

Submit your manuscript at www.biomedcentral.com/submit
(OioMed Central 